\title{
Lactic acid bacteria dynamics during spontaneous fermentation of cocoa beans verified by culture-independent denaturing gradient gel electrophoresis
}

\author{
T.F. Santos*, L.K.A. Santana*, A.C.F. Santos, G.S. Silva, C.C. Romano, \\ J.C.T. Dias and R.P. Rezende \\ Laboratório de Biotecnologia Microbiológica, \\ Departamento de Ciências Biológicas, Universidade de Santa Cruz, \\ Ilhéus, BA, Brasil \\ *These authors contributed equaly to this study. \\ Corresponding author: R.P. Rezende \\ E-mail: rachel@uesc.br
}

Genet. Mol. Res. 10 (4): 2702-2709 (2011)

Received December 2, 2010

Accepted July 29, 2011

Published November 4, 2011

DOI http://dx.doi.org/10.4238/2011.November.4.3

\begin{abstract}
Cocoa is naturally fermented in the field before the cocoa seeds are removed for processing. We assessed the dynamics of lactic acid bacteria during cocoa fermentation in Bahia, Brazil. During five days of fermentation, temperature and $\mathrm{pH}$ were measured and beans were collected for genomic DNA extraction every $12 \mathrm{~h}$. The DNA was used as a template for amplification with Lac1-Lac2 and Lac3-Lac2 for denaturing gradient gel electrophoresis analyses. $\mathrm{pH}$ values ranged from 3.34 to 4.98 , while the temperature varied from $23^{\circ}$ to $50^{\circ} \mathrm{C}$. Lac1-Lac2 primers permitted detection of 11 operational taxonomic units. Twentyeight operational taxonomic units were obtained with the primer pair Lac3-Lac2. It was observed that there were variations between the numbers of operational taxonomic units throughout the process, probably because of changes in $\mathrm{pH}$ and temperature. The greatest similarity in
\end{abstract}


amplified samples was obtained with the primers Lac3-Lac2.

Key words: Lac1; Lac2; Lac3; Cocoa; DGGE; Lactic acid bacteria

\section{INTRODUCTION}

Cocoa bean fermentation is the first step in making chocolate, followed by drying, roasting and processing. In these steps, color, flavor and aroma characteristics are developed. The ecology of this process has been studied in order to produce better quality chocolate, which would be economically advantageous to producing countries, like Ivory Coast, Ghana and Brazil (Camu et al., 2007).

After harvest and fruit opening, almonds are packed in boxes, baskets, trays, or stacked in heaps covered with banana leaves, depending on the regional tradition (Nielsen et al., 2008). The fermentation consists of a microbial succession composed of yeast, lactic acid bacteria and acetic acid bacteria. Early in the process, yeasts are favored due to high sugar concentration, low oxygen availability and low $\mathrm{pH}$. They consume citric acid-producing ethanol, and present pectinolytic activity. The reduced oxygen availability, combined with increased temperature and $\mathrm{pH}$, favor the development of lactic bacteria, which consume citric acid and ferment sugars to lactic acid. The increased aeration, due to pectin degradation, promotes the development of acetic bacteria, which ferment the ethanol, a highly exothermic process. Ethanol and acetic acid diffuse into the embryo, which coupled with the increase in temperature causes their death (Schwan and Wheals, 2004; Jespersen et al., 2005; Nielsen at al., 2007). As in other microbial groups, lactic acid bacteria promote biochemical changes that contribute to the development of chocolate flavor.

Lactic acid bacteria convert glucose, fructose and citrate to lactic acid, acetic acid, ethanol and mannitol. They are especially important in citrate fermentation, since few species of yeast isolated from the fermentation of cocoa do. The rise in $\mathrm{pH}$ and formation of other acids and ethanol favor the heterogeneity of this group of microorganisms. Thus, some species are found early in the process, while others stand out in the later stages of fermentation. Importantly, some species of lactic acid bacteria, including Lactobacillus plantarum and L. fermentum, are capable of producing antimicrobial substances, which play an important role in bacterial ecology (Camu et al., 2007).

There are few articles that aim to study the dynamics of lactic acid bacteria in this process. Research conducted in Nigeria, Indonesia and Ghana have identified the predominance of the Lactobacillus genus, but Pediococcus, Leuconostoc and Lactococcus also stand out (Ardhana and Fleet, 2003; Camu et al., 2007; Kostinek et al., 2008). The difficulty in accessing the full biodiversity of this microbial group in this process is related to the limitations of culture-dependent methods, which are predominant in classical microbiological studies (Schwan and Wheals, 2004). Culture-independent molecular techniques are therefore a viable alternative in the study of complex microbial communities, enabling the detection of species not detectable by traditional methods.

In 2001, Walter et al. developed the primer pair Lac1-Lac2 to optimize detection of Lactobacillus in human feces, and in 2005, Endo and Okada designed the primer Lac3, a variation of Lac1, which increased the number of genera of lactic acid bacteria detectable using these primers. 
In this study, PCR-DGGE was used to assess the dynamics of lactic acid bacteria during cocoa fermentation, using specific primers: Lac1-Lac2 and Lac3-Lac2.

\section{MATERIAL AND METHODS}

\section{Sampling}

The fermentation was carried out on the farm São Jorge, in Ilhéus $\left(14^{\circ} 47^{\prime} 20^{\prime \prime} 39^{\circ}\right.$ $02 ' 58 ")$, in wooden boxes with a capacity of $800 \mathrm{~kg}$.

Every $12 \mathrm{~h}$ the fermentative mass was rotated and $200 \mathrm{~g}$ almonds was tacked in the center of the fermentation box and immediately sent to the laboratory for analysis. Fermentation lasted five days.

\section{pH and temperature measurement}

Every $12 \mathrm{~h}$, temperature and $\mathrm{pH}$ were measured. The average temperature was determined by placing a thermometer in the center of the fermentation box, about $60 \mathrm{~cm}$ from the surface. The pulp was separated from the beans mechanically by shaking vigorously in a plastic bag together with distilled water in a 1:1 ratio. The pulp-decanted fraction was collected for $\mathrm{pH}$ measurement using a $\mathrm{pH}$ meter.

\section{DNA extraction}

The samples were processed in a pulper with saline $(0.9 \% \mathrm{NaCl})$ plus $0.1 \%$ Tween. Each sample of pulp was homogenized in a vortex for $30 \mathrm{~s}$. An aliquot of $5 \mathrm{~g}$ was centrifuged at $3000 \mathrm{~g}$ for $5 \mathrm{~min}$. Subsequently, the samples were washed once in TE buffer (Tris base, EDTA) 50/50 and six times in PBS (1.37 M NaCl, $27 \mathrm{mM} \mathrm{KCl}, 100 \mathrm{mM} \mathrm{Na}_{2} \mathrm{HPO}_{4}, 20 \mathrm{mM}$ $\left.\mathrm{KH}_{2} \mathrm{PO}_{4}\right) 0.1 \mathrm{M}, \mathrm{pH}$ 8. Then, they were subjected to sonication with an amplitude of $20 \%$ and absent pulse in two 40-s series. Two series of 1 min were used only in the samples of 0 , 12,24 , and $36 \mathrm{~h}$, with a six-second pulse on and a two-second pulse off. The samples were centrifuged at $100 \mathrm{~g}$ for $3 \mathrm{~min}$ and the supernatant was discarded. A further centrifugation was then performed at $3000 \mathrm{~g}$. The pellet was suspended in TESC $(10 \mathrm{mM}$ Tris-HCl, $1 \mathrm{mM}$ EDTA, $0.1 \mathrm{mM} \mathrm{NaCl}, \mathrm{pH} 8.3$ ) and subjected to enzymatic lyses with $3 \%$ proteinase $\mathrm{K}$ and $20 \%$ SDS. The physical lysis was performed in three cycles of thermal shock $\left(-196^{\circ} \mathrm{C}\right.$ for $40 \mathrm{~s}$ and $90^{\circ} \mathrm{C}$ for $5 \mathrm{~min})$, followed by phenol-chloroform-isoamylic alcohol (25:24:1) extraction. DNA was precipitated with $10 \%$ sodium acetate and $70 \%$ isopropanol. The solution was maintained at $-20^{\circ} \mathrm{C}$ for $16 \mathrm{~h}$ and subsequently centrifuged for $10 \mathrm{~min}$ at $3000 \mathrm{~g}$. The precipitate was washed twice with $70 \%$ ethanol and suspended in ultrapure water. The extracted DNA was purified using the Wizard DNA kit Clean-Up System $\left(\right.$ Promega $\left.^{\circledR}\right)$.

\section{PCR}

Each DNA sample was subjected to amplification using the primers Lac1 (5'-AGCAGTAGGGAATCTTCCA-3') or Lac3 (5'-AGCAGTAGGGAATCTTCCA-3') and reverse primer Lac 2 GC (5'-CGCCCGGGGCGCGCCCCGGGCGGCCCGGGGGCACCGG 
GGGATTYCACCGCTACACATG-3'). Each $50 \mu \mathrm{L}$ mix contained 25 pmol of each primer, $0.2 \mathrm{mM}$ each dNTP, $1 \mathrm{X}$ buffer, $3.7 \mathrm{mM} \mathrm{MgCl}, 0.4 \mathrm{mg} / \mathrm{mL}$ BSA, $2.85 \mathrm{U}$ Taq polymerase and 10 ng DNA. The amplification process consisted of an initial denaturation step at $94^{\circ} \mathrm{C}$ for 2 min followed by 35 cycles of $1 \mathrm{~min}$ at $94^{\circ} \mathrm{C}, 2 \mathrm{~min}$ at $60^{\circ} \mathrm{C}$ and $1 \mathrm{~min}$ at $72^{\circ} \mathrm{C}$ and a final step of extension at $72^{\circ} \mathrm{C}$ for $30 \mathrm{~min}$.

\section{DGGE}

To make the gel, two stock solutions of $8 \%$ acrylamide (37.5 acrylamide: 1 bis-acrylamide) diluted in 1X TAE buffer (TAE50X - 2 M Tris base, glacial acetic acid and $1 \mathrm{M} 50$ mM EDTA) were prepared. One of these solutions contained $40 \%(\mathrm{v} / \mathrm{v})$ formamide and $7 \mathrm{M}$ urea. The gels, made by the proportional mix of these two solutions, formed an increasing denaturing gradient of $35-65,20-70$ and $20-50 \%$ in the electrophoresis direction. Electrophoresis was performed with a constant voltage of $200 \mathrm{~V}$ at $60^{\circ} \mathrm{C}$ for $4 \mathrm{~h}$ in $1 \mathrm{X}$ TAE buffer. The gels were stained with $2 \%$ solution of silver nitrate following the protocol of Beidler et al. (1982) modified by Creste et al. (2001). The presence or absence of bands was detected after gel image processing, using the PhotoFiltre program. The Dice similarity coefficient was used to compare the microbial dynamics between the collection times. Similarity between samples was determined based on the presence or absence of bands. This coefficient is calculated from the formula $(\mathrm{Cs})=2 \mathrm{j} /(\mathrm{a}+\mathrm{b})$, where $a$ and $b$ represent the number of bands present in each sample analyzed, and $j$ the number of bands in common for samples $a$ and $b$. The resulting dendrogram shows clustering according to similarity of banding patterns between samples.

\section{RESULTS AND DISCUSSION}

The microbial diversity found in this process has an environmental origin, and contamination occurs due to the handling and packaging of seeds (Schwan and Wheals, 2004). The temperature and $\mathrm{pH}$ during fermentation of cocoa are critical points that reveal the microbial succession and metabolism. pH values ranged between 3.34 and 4.98, whereas the highest values were recorded from $60 \mathrm{~h}$ (Figure 1A). In Ghana, Nielsen et al. (2007) and Camu et al. (2007) found similar values ranging from 3.94 to 4.69 and 3.5 to 4.3 , respectively. Nielsen et al. (2007) highlighted the importance of volatile acid evaporation at high $\mathrm{pH}$, especially in the final stages of fermentation. In Indonesia, Ardhana and Fleet (2003) observed similar behavior with respect to acidity of the pulp. The $\mathrm{pH}$ of 3 is critical to lactic acid bacteria. Studies that test the probiotic potential of these organisms show that they can remain viable in this acidic condition, but their growth may be retarded (Zoumpopoulou et al., 2008).

During fermentation, temperatures reached $23^{\circ}$ to $50^{\circ} \mathrm{C}$, averaging $28.3^{\circ} \mathrm{C}$ in the first $36 \mathrm{~h}$ and $48.2^{\circ} \mathrm{C}$ for the rest of the process (Figure 1B). Studies on cocoa fermentation in Ghana and Indonesia showed the same temperature variation pattern. The increased temperature after $48 \mathrm{~h}$ coincides with the growth of acetic bacteria. The conversion of ethanol to acetic acid is a highly exothermic process. The release of heat in this reaction is probably responsible for the abrupt rise in temperature at the end of the second day of fermentation. This variable can be influenced by the process of tilling the fermenting dough, since the increase in aeration favors the action of acetic bacteria (Schwan and Wheals, 2004; Camu et al., 2008). 

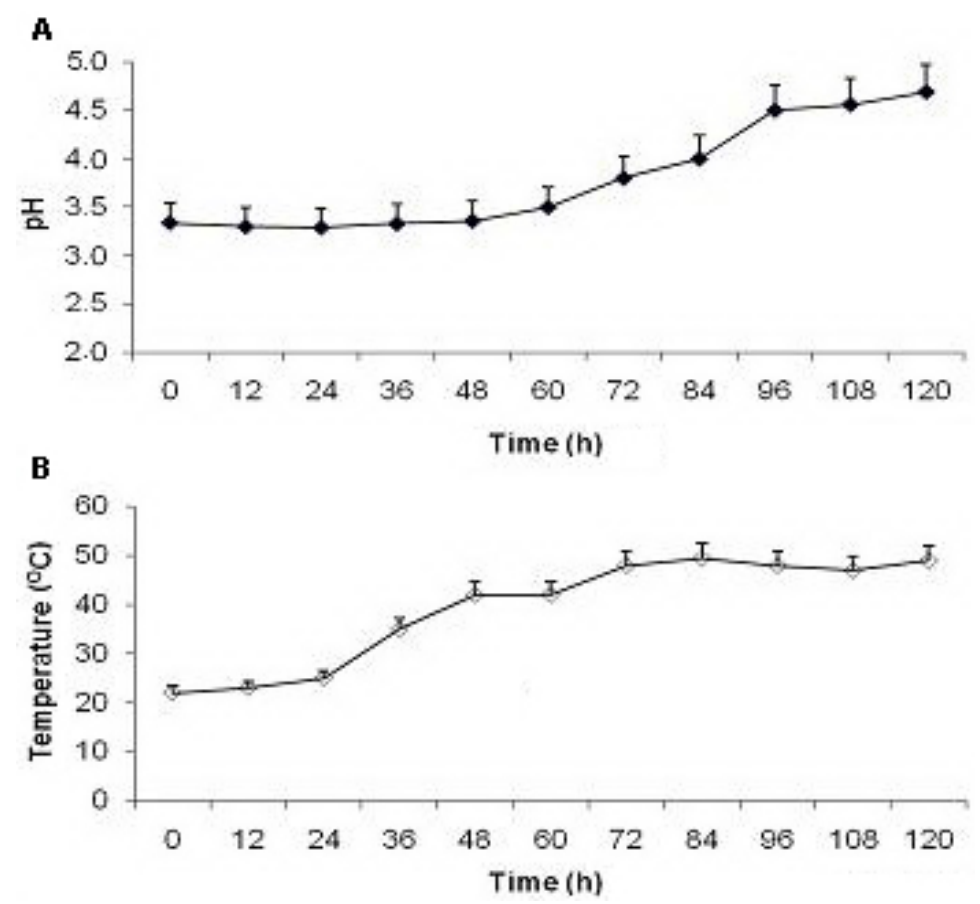

Figure 1. $\mathrm{pH}$ variation during fermentation. A. Temperature variation during fermentation. B. Error bar indicates standard deviation.

Due to the large amount of organic matter and viscosity of the pulp, the extraction of DNA has become an obstacle. Kits and protocols tested in other laboratories were not successful. The only method that has proven to be effective for the direct extraction of genomic DNA from the cocoa pulp was an adaptation of standardized methodology developed by Maciel et al. (2009). Accordingly, to overcome technique limitations, washing times were increased and we chose a combination of physical, chemical and enzymatic lysis methods. These interventions may have contributed to the failure to detect less abundant bacteria. This is a limitation of the technique; however, during the process standardization of extraction of genomic DNA, these steps were essential for obtaining a functional sample. This protocol allowed the extraction of a large amount of DNA; however, we must emphasize the importance of purification steps, due to the presence of contaminants such as phenols and organic acids that could interfere with the amplification process. The amplification produced fragments of about 345 bp for both primer pairs.

Considering the Lac1-Lac2 pair, the DGGE gel showed a maximum of 11 OTUs (operational taxonomic units), observed mainly between 36 and $48 \mathrm{~h}$ (Figure 2A). According to Walter et al. (2001), lactic acid bacteria of the Lactobacillus, Pediococcus, Leuconostoc, and Weisella genus can be detected using this primer pair. Through the DICE correlation, the fermentation could be divided into two groups, the first $72 \mathrm{~h}$ of fermentation with $72 \%$ similarity, and the second group, from $84 \mathrm{~h}$ until the end of the process with $60 \%$ similarity (Figure 2B). Similarities of $100 \%$ were observed in samples collected between 0 and $12 \mathrm{~h}$, between 36 and 
$48 \mathrm{~h}$ and between 108 and $120 \mathrm{~h}$. Lac2-Lac3 primers (Endo and Okada, 2005) can amplify lactic bacteria of the Lactococcus, Streptococcus, Enterococcus, Tetragenococcus, and Vagococcus genera. Using this primer pair, we observed a maximum of 28 OTUs, and of these, 18 were between 24 and $72 \mathrm{~h}$ (Figure 3A). There was a similarity of $84 \%$ in the first $48 \mathrm{~h}$ of fermentation, especially for those collected between 24 and $48 \mathrm{~h}$ with $100 \%$ similarity, according to the DICE correlation (Figure 3B).

A

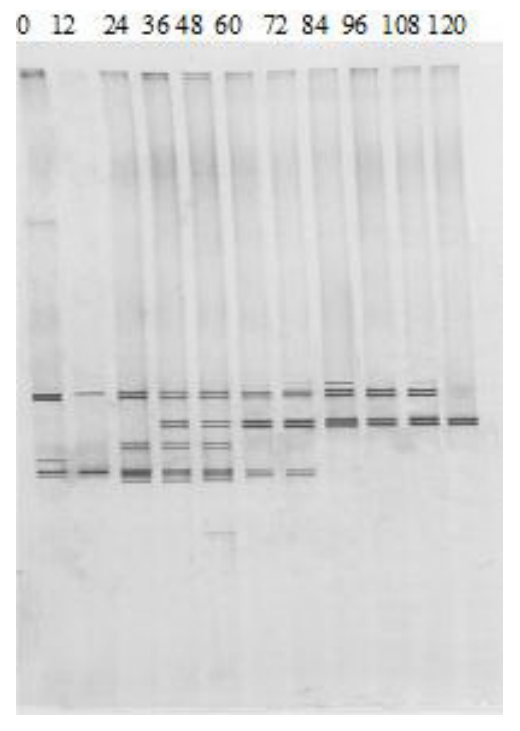

B

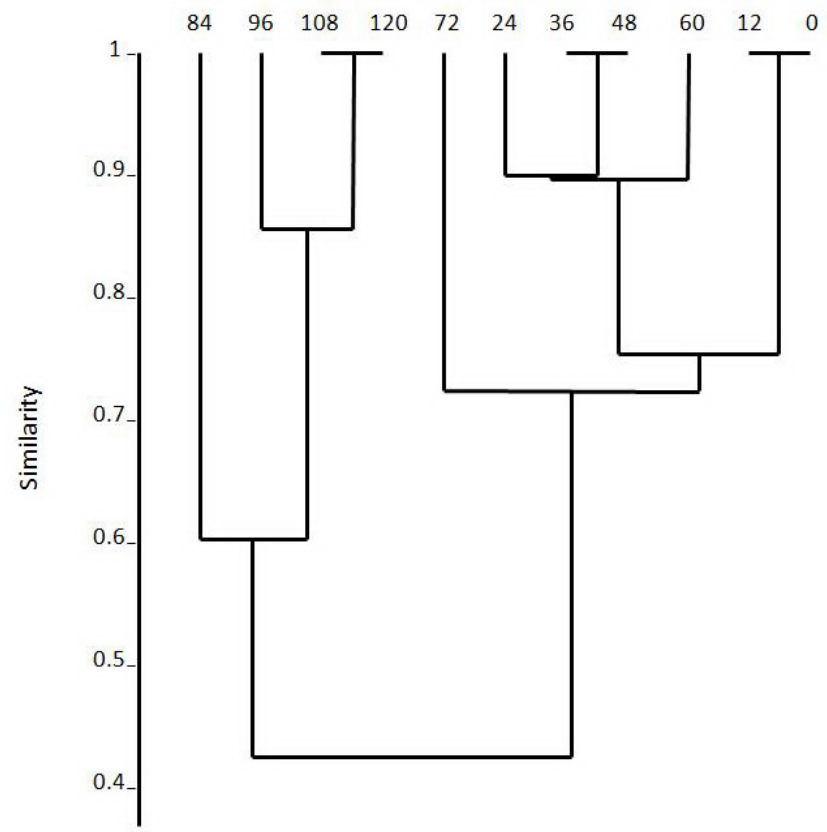

Figure 2. Dynamics of the lactic acid bacteria population in cocoa fermentation by DGGE using PCR products amplified with primers Lac1-Lac2. A. The sequence indicated on gel refers to the time of sampling in hours. B. Graph of the similarity of the lactic acid bacteria population in cocoa fermentation through Dice correlation, using PCR products amplified with primers Lac1-Lac2.

The temperature and $\mathrm{pH}$ conditions on the second day of fermentation probably are responsible for the detection of a larger number of OTUs between 36 and $48 \mathrm{~h}$ and 24 and 72 $\mathrm{h}$, for each pair of primers respectively. The temperature elevation at the end of fermentation, as well as the limited availability of sugar, coupled with a rise in $\mathrm{pH}$ should have favored the shift in community profile observed after $84 \mathrm{~h}$ of fermentation, which was detected mainly by the pair Lac1-Lac2. The bacterial groups that are targets of the pair Lac3-Lac2 may be more resistant to environmental changes, since they showed greater similarity to the process.

Primers Lac1-Lac2 and Lac3-Lac2 have been used in the study of populations of lactic acid bacteria in food or in the intestinal tract of humans and other animals (Walter et al., 2001; Endo and Okada, 2005). Camu et al. (2008) used the pair Lac1-Lac2 to observe the dynamics of lactic acid bacteria in cocoa and especially highlighted the participation of the genus Lactobacillus. Our study is the first to use two primer pairs in the study of the lac- 
A

$0 \quad 1224364860728496108120$

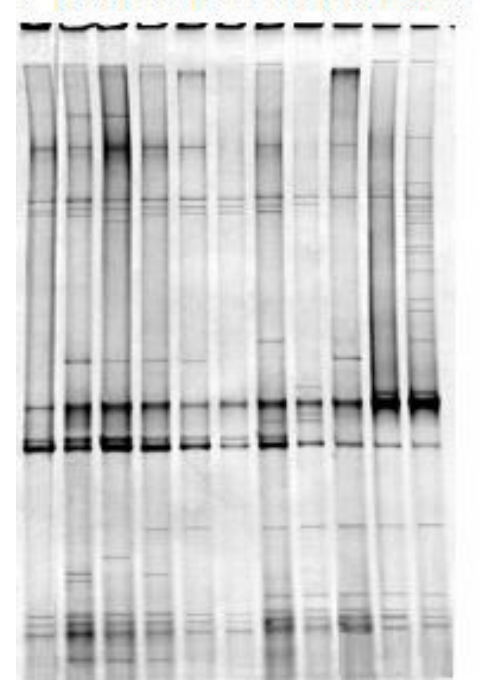

B

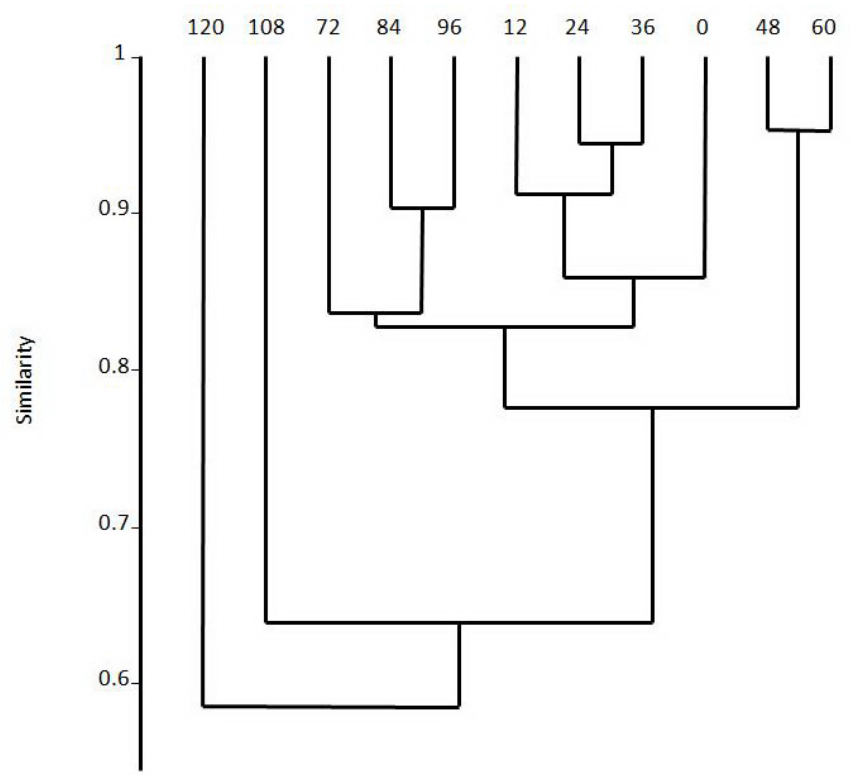

Figure 3. Dynamics of the lactic acid bacteria population in cocoa fermentation by DGGE using PCR products amplified with primers Lac2-Lac3. A. The sequence indicated on gel refers to the time of sampling in hours. B. Graph of the similarity of the lactic acid bacteria population in cocoa fermentation through Dice correlation, using PCR products amplified with primers Lac2-Lac3.

tic fermentation in cocoa. The high number of OTUs and the similarity between the samples reveal that the microbial group detected by the pair Lac3-Lac2 may have an important role during fermentation, contributing to the development of parameters such as the final acidity of the seed, a critical point for the development of chocolate flavor. Given the importance of cocoa bean fermentation in the chocolate manufacturing process, its study becomes crucial. Our study underscored the usefulness of DGGE as a tool to study the dynamics of lactic acid bacteria during this process. Greater diversity was observed around the second day of fermentation and the decrease in detection capability in the final stages could be related to adverse environmental conditions or contaminants in the sample that may have interfered with the amplification. Moreover, the observed population using primers Lac3-Lac2 was less affected, so it is necessary to study the participation of the microbial group targeted by this primer pair in this process.

\section{ACKNOWLEDGMENTS}

Research supported by Conselho Nacional de Desenvolvimento Científico e Tecnológico (CNPq - Process \#502697/2003-2) and the Universidade Estadual de Santa Cruz (UESC). The financial support granted to L.K.A. Santana and G.S. Silva was provided by Fundação de Amparo à Pesquisa do Estado da Bahia (FAPESB). 


\section{REFERENCES}

Ardhana MM and Fleet GH (2003). The microbial ecology of cocoa bean fermentations in Indonesia. Int. J. Food Microbiol. 86: 87-99.

Beidler JL, Hilliard PR and Rill RL (1982). Ultrasensitive staining of nucleic acids with silver. Anal Biochem. 126: $374-$ 380.

Camu N, De Winter T, Verbrugghe K, Cleenwerck I, et al. (2007). Dynamics and biodiversity of populations of lactic acid bacteria and acetic acid bacteria involved in spontaneous heap fermentation of cocoa beans in Ghana. Appl. Environ. Microbiol. 73: 1809-1824.

Camu N, Gonzalez A, De Winter T, Van Schoor A, et al. (2008). Influence of turning and environmental contamination on the dynamics of populations of lactic acid and acetic acid bacteria involved in spontaneous cocoa bean heap fermentation in Ghana. Appl. Environ. Microbiol. 74: 86-98.

Creste S, Tulmann Neto A and Figueira A (2001). Detection of single sequence repeat polymorphisms in denaturing polyacrilamide sequencing gels by silver staining. Plant Mol. Biol. Rep. 19: 299-306.

Endo A and Okada S (2005). Monitoring the lactic acid bacterial diversity during shochu fermentation by PCR-denaturing gradient gel electrophoresis. J. Biosci. Bioeng. 99: 216-221.

Jespersen L, Nielsen DS, Honholt S and Jakobsen M (2005). Occurrence and diversity of yeasts involved in fermentation of West African cocoa beans. FEMS Yeast Res. 5: 441-453.

Kostinek M, Ban-Koffi L, Ottah-Atikpo M, Teniola D, et al. (2008). Diversity of predominant lactic acid bacteria associated with cocoa fermentation in Nigeria. Curr. Microbiol. 56: 306-314.

Maciel BM, Santos AC, Dias JC, Vidal RO, et al. (2009). Simple DNA extraction protocol for a 16S rDNA study of bacterial diversity in tropical landfarm soil used for bioremediation of oil waste. Genet. Mol. Res. 8: 375-388.

Nielsen DS, Teniola OD, Ban-Koffi L, Owusu M, et al. (2007). The microbiology of Ghanaian cocoa fermentations analysed using culture-dependent and culture-independent methods. Int. J. Food Microbiol. 114: 168-186.

Nielsen DS, Snitkjaer P and van den Berg F (2008). Investigating the fermentation of cocoa by correlating denaturing gradient gel electrophoresis profiles and near infrared spectra. Int. J. Food Microbiol. 125: 133-140.

Schwan RF and Wheals AE (2004). The microbiology of cocoa fermentation and its role in chocolate quality. Crit. Rev. Food Sci. Nutr. 44: 205-221.

Walter J, Hertel C, Tannock GW, Lis CM, et al. (2001). Detection of Lactobacillus, Pediococcus, Leuconostoc, and Weissella species in human feces by using group-specific PCR primers and denaturing gradient gel electrophoresis. Appl. Environ. Microbiol. 67: 2578-2585.

Zoumpopoulou G, Foligne B, Christodoulou K, Grangette C, et al. (2008). Actobacillus fermentum ACA-DC 179 displays probiotic potential in vitro and protects against trinitrobenzene sulfonic acid (TNBS)-induced colitis and Salmonella infection in murine modelsInternational. Int. J. Food Microbiol. 121: 18-26. 